\title{
Psicooncología
}

ISSN: 1696-7240

\section{To disclose or not to disclose? Communication between mothers with cancer and their young children}

\author{
Ana Luísa Kenne Dornel ${ }^{1}$; Miguel Luis Alves de Souza²; Elisa Kern de Castro ${ }^{3, *}$
}

Recibido: 3 de julio de 2018 / Aceptado: 20 de agosto de 2018

\begin{abstract}
Objective: Understand how mothers with cancer communicate about the disease with their children. Method: We used qualitative methods. Ten mothers participated in a semi-structured interview about their experiences of disclosing the disease to their young children. The interviews were audio recorded and transcribed. Results: Two main themes emerged, including three sub-themes for the second theme: 1) The cancer was disclosed to the children; 2) The cancer was not disclosed to the children; 2.1 Did not tell her child and has no intention to do so; 2.2 Did not tell her child but plans to do so in the future; and 2.3 Did not tell her child but believes her child knows about the disease. Mothers who succeed in maintain a sincere dialogue with their children show a strong affective closeness with their children. Conclusions: The findings may be useful for understanding and planning communication strategies that favor the mother-child bond and that positively contribute to the treatment of mothers with cancer.
\end{abstract}

Keywords: cancer; communication; maternity; mother-child; oncology.

\section{[es] ¿Revelar o no revelar? Comunicación entre madres con cáncer y sus hijos pequeños}

Resumen: Objectivo: comprender cómo madres con cáncer se comunican sobre su enfermedad con sus hijos. Método: diseño cualitativo. Diez madres participaron de una entrevista semi-estructurada sobre sus experiencias de revelación de la enfermedad a sus hijos pequeños. Las entrevistas fueron grabadas en audio y transcritas. Resultados: dos temas principales fueron identificados, y el segundo tema contiene tres sub-temas: 1) el cáncer fue revelado a los niños; 2) el cáncer no fue revelado a los niños; 2.1 no reveló al niño y no hay la intención de hacerlo; 2.2 no reveló al niño pero hay planos de hacerlo en el futuro; y 2.3 reveló al niño pero cree que él sabe sobre la enfermedad. Las madres que lograron mantener un diálogo sincero con sus niños fuerte cercanía afectiva con sus hijos. Conclusiones: Los hallazgos pueden ser útiles para comprender y planear estrategias de comunicación que favorezcan el vínculo madre-hijo y que contribuyan de manera positiva al tratamiento de las madres con cáncer.

Palabras clave: Cáncer; comunicación; maternidad; madre-hijo; oncología.

1 Ana Luísa Kenne Dornel

Programa de Pós-Graduação em Psicologia, Centro de Ciências da Saúde. São Leopoldo, RS, Brazil.

E-mail: anakdornel@yahoo.com.br

2 Miguel Luis Alves de Souza

Programa de Pós-Graduação em Psicologia, Centro de Ciências da Saúde. São Leopoldo, RS, Brazil.

E-mail: mlalvesdesouza@outlook.com

3 Elisa Kern de Castro

Programa de Pós-Graduação em Psicologia, Centro de Ciências da Saúde. São Leopoldo, RS, Brazil

E-mail: elisakc@unisinos.br

* Dirección de correspondência: Elisa Kern de Castro. Programa de Pós-Graduação em Psicologia, Centro de Ciências da Saúde. Avenida Unisinos 950, bairro Cristo Rei, CEP 92022-000, São Leopoldo, RS, Brazil. E-mail: elisakc@unisinos.br 
Sumario. 1. Introduction 2. Objectives 3. Method 3.1. Eligibility and enrollment 3.2. Data collection 3.3. Qualitative analysis 4. Results 5. Conclusion 6. References

Cómo citar: Kenne Dornel AL, Alves de Souza ML, Kern de Castro E. To disclose or not to disclose? Communication between mothers with cancer and their young children. Psicooncología 2018;15:237248. doi: 10.5209/PSIC.61433.

\section{Introduction}

A recurrent concern among mothers with cancer is how to approach and what to say when talking to their children about the disease ${ }^{(1,2)}$. A cancer diagnosis may have a strong psychological impact on patients as well as their relatives, causing changes in relationships among all family members ${ }^{(3-5)}$. For the child, the mother's illness may cause deep suffering, typically expressed as anger, concern and behavioral changes, which may in turn exacerbate the mother's concern about how to respond to the situation ${ }^{(3,6-8)}$. Besides that, it is important to consider that children of parents that have cancer are more susceptible to develop emotional problems than adolescents or adults. This occurs because they are on an initial stage of development, and have less cognitive abilities to cope and understand the situation, and still needs the parents care ${ }^{(9)}$. Thus, the children may shows exacerbate reactions to mother's absence, such as cry, difficult to sleep and difficult to separate from the mother ${ }^{(8)}$. Furthermore, mothers may feel insecure about the child's ability to understand and cope with their health status, which may make them uncertain about how to disclose the diagnosis to their child ${ }^{(2)}$.

Ambivalence concerning whether to disclose the cancer diagnosis to the child occurs frequently because, on the one hand, mothers may want to conceal the diagnosis to protect their children from suffering. And, on the other hand, mothers struggle to hide the disease from their children for a long time due to changes in their physical appearance and in the family routine $e^{(2,6)}$. The lack of disclosure does not prevent the child from noticing symptoms and from thinking about the mother's possible death, particularly when the changes are more visible ${ }^{(10) 6,8}$ or 10 years. When mothers decide to disclose the diagnosis, they may struggle considerably in discussing the disease with their children because they do not know how to do so, including which terms to use ${ }^{(2,5)}$. In addition, parents may perceived a lack of guidance from the healthcare providers about how or when talk to their children. This is possible to understand because some professionals, such as oncologists and nurses, may feel unable to respond adequately to parent's needs because they do not know how to support the family or even believe that talking about their children may increase parent's distress ${ }^{(9)}$. Therefore, it is important to provide training for health providers, so they can aware parents about the importance and benefits from an open communication with their children about mother's disease, and provide guidance of how to do this ${ }^{(3,9,11)}$.

Studies indicate that factors such as a lack of communication or difficulties in creating space for dialogue about the mother's disease may create new family conflicts or exacerbate existing ones ${ }^{(12-14)}$, in addition to aggravating emotional problems in mothers and children ${ }^{(3)}$. Negative consequences of the lack of communication include emotional distancing between mother and child, lack of mutual support, increased child anguish and anxiety from not understanding 
what is happening to the mother, and the propensity of the child to develop psychological problems, such as depression ${ }^{(3,4)}$. Therefore, some studies argue that being forthright about the mother's disease may be the best approach ${ }^{(12,14,15)}$.

Despite existing doubts and uncertainties, open communication with the child may decrease mothers' depression levels, improve their disease-coping strategies ${ }^{(2)}$ and enhance tranquility ${ }^{(1)}$. For the children, this openness in communication may help reduce their anxiety levels about the mother's disease ${ }^{(1,2)}$. Therefore, communication between mothers and children in situations of maternal cancer appears to favor the mother-child bond and fosters emotional support ${ }^{(14)}$, regulates emotions, enhances dialogue ${ }^{(16)}$ and helps with the necessary family adaptations imposed by the disease ${ }^{(17,11)}$.

Although there is some guidance about how mothers communicate about the disease with their adolescent children ${ }^{(11)}$, there is no clear guidance or rule concerning how mothers should communicate with a young child about their cancer. Depending on the level of development, the child may understand death and disease differently; therefore, limitations in the child's capacity to digest information must be acknowledged and respected, choosing language appropriate to the child's level of understanding.

\section{Objectives}

We conducted a qualitative study to understand how mothers with cancer communicate about the disease with their child(ren). We chose mothers who have children up to ten years of age because this is the age that characterizes childhood according World Health Organization (WHO) ${ }^{(18)}$. Besides, during this period of life, children require the mother's emotional and physical dedication to their care, like help them with school and other activities, or even preparing meals and packing lunches ${ }^{(3)}$. The mother's illness may impair daily activities with her child and may increase her anguish due to the risk of death and fear of leaving the child motherless during childhood. Our aim is to characterize the experience of cancer in mothers and how and why they disclose (or not) the diagnosis to their child.

\section{Method}

\subsection{Eligibility and enrollment}

We selected patients from the League Against Cancer of a southern Brazilian city from March to June 2016. The selected patients were women diagnosed with any type of cancer, in any phase of treatment, and with at least one child up to 10 years of age. To maintain the confidentiality of the participants, we used flower names to identify the mothers in the present paper. This study was approved by the Ethics Committee.

\subsection{Data collection}

We developed a semi-structured qualitative interview script to facilitate the collection of information concerning how mothers communicate with their children about cancer. The questions that we used on the interview were: Do you talk to your child(ren) about your disease and your treatment? What does she or he knows? What she or he 
doesn't know yet? Mothers who have children over to ten years old were instructed to respond the questions about their communication with the youngest child. The same trained interviewer (psychologist) conducted all interviews. All participants were accessed by indication of a non-governmental organization. Mothers were contacted by telephone by the researcher, who explained the research objectives and invited them to participate in the study. The interviews were conducted in person at the women's homes and were audio recorded and transcribed for analysis.

\subsection{Qualitative analysis}

The data from the interviews were analyzed qualitatively. The thematic content of the transcribed interviews was analyzed ${ }^{(19)}$ to identify similarities and peculiarities in the participants' reports according to the theme of the study. The Consolidated criteria for reporting qualitative research (COREQ) protocol was used, which is a 32 -item checklist that ensures the quality criteria of a qualitative scientific article using interview or focus groups are satisfied ${ }^{(20)}$. In total, 4 hours and 30 minutes of recordings were transcribed.

Data were analyzed in three stages: a) an initial naïve reading; b) structural analysis and content categorization; and c) critical interpretation and discussion. Three researchers conducted the analysis to create the categories. Subsequently, another two researchers, who were considered independent raters, assessed the content of the interviews and categorized the content according to the categories previously created based on emerging themes. The degree of inter-rater agreement was assessed using the Kappa index, which was found to be 0.844 .

\section{Results}

Of the 12 women selected to participate in the study, one rejected the invitation, and another was excluded because she was in the postpartum period. Thus, ten women participated. The sociodemographic and clinical data of the participants are outlined in Table 1.

The analysis of the mothers' reports on the topic of communication with their children about cancer revealed two thematic categories, with Category 2 including three subcategories.

Category 1: Cancer was disclosed to the children

The mothers' statements show that the diagnosis is disclosed to children differently, including the use of stories about relatives who had the same disease, as illustrated by the following statement by the participant Violet:

"They [the daughters] insistently asked how and of what did their grandfather and grandmother die. I said that it was cancer, and then I described it and where it hurt". Yesterday she [daughter] commented, "Mom, grandmother took a shot [injection] in the butt. This is why she died". Then, I replied: "No, daughter, it was cancer, just like I have, but grandmother took too long to see a doctor. I went right away; as soon as I found out, I went to see a doctor". (Violet) 


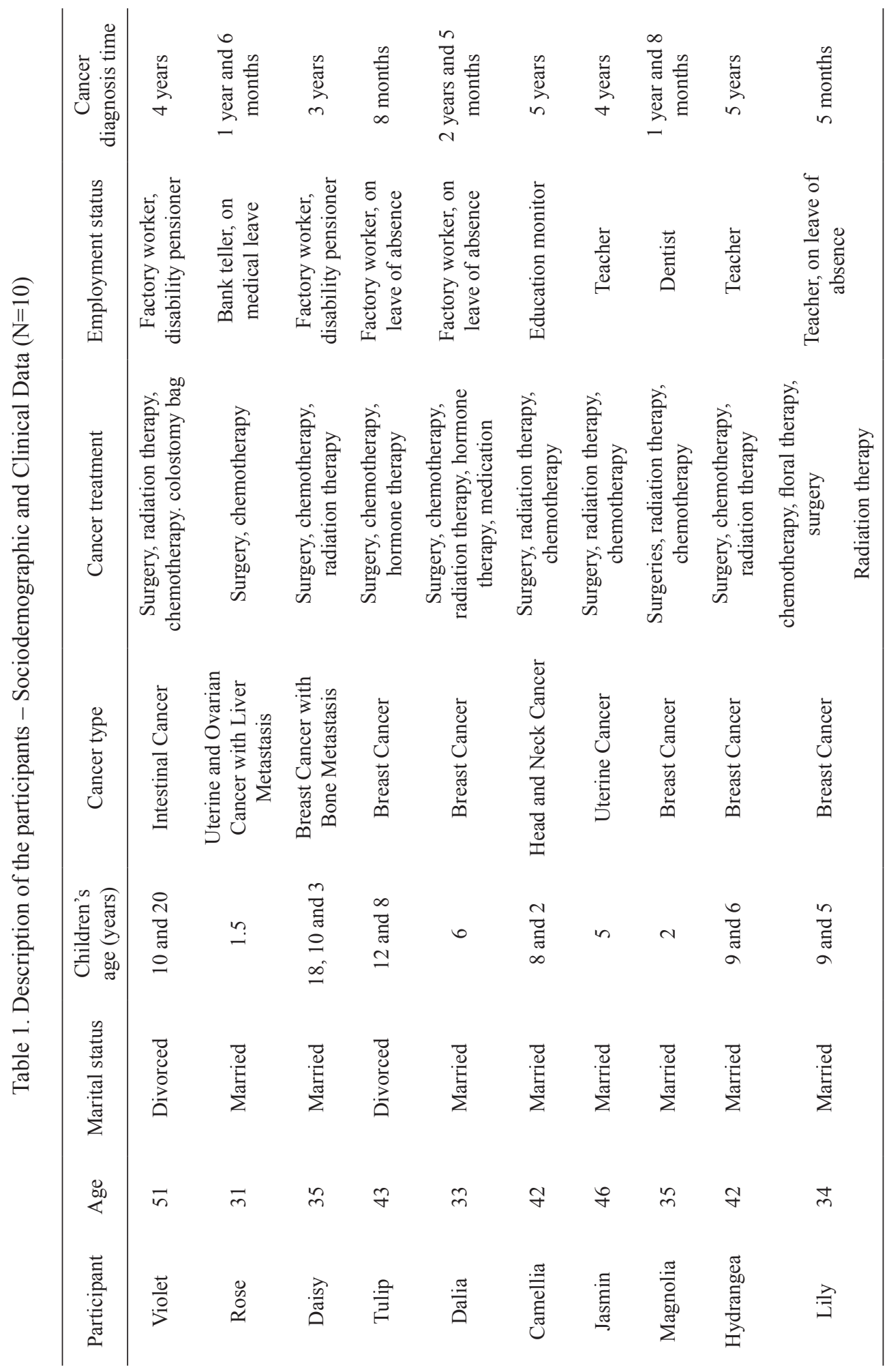


Table 2. Categories generated based on the theme of mother-child communication about cancer

\begin{tabular}{lll}
\hline $\mathrm{N}^{\mathrm{o}}$ & \multicolumn{1}{c}{ Category } & \multicolumn{1}{c}{ Description } \\
\hline 1 & $\begin{array}{l}\text { Cancer was disclosed to chil- } \\
\text { dren }\end{array}$ & $\begin{array}{l}\text { Reports of mother-child conversations in which the } \\
\text { mothers clearly and objectively provide informa- } \\
\end{array}$ \\
& $\begin{array}{l}\text { tion on the disease and on cancer treatment, some- } \\
\text { times using resources and stories as examples. }\end{array}$
\end{tabular}

2 Cancer was not disclosed to children

2.1 Mother did not disclose the cancer to the child and has no intention to do so

2.2 Mother did not disclose the cancer to the child but plans to do so in the future

2.3 Mother did not disclose the cancer to the child but believes that the child knows about the disease
Reports of mothers who stated they did not talk to their child(ren) about the disease/treatment.

Reports of mothers who expressed that they did not disclose their disease or talk about treatment with their children and who did not mention that they will broach either topic in the future.

Reports of mothers who expressed their desire to talk to their children about the disease and cancer treatment in the future.

Reports of mothers who said that they did not talk about the disease or cancer treatment, but who believed that their children realized they were sick.

Violet apparently realized that the child was already showing signs of understanding her disease and thus used the grandmother's story to explain her own disease, carefully softening the situation. Providing honest information adapted to the child's language may enhance communication, thereby curbing the child's curiosity and concern ${ }^{(3)}$. Children are unsurprisingly curious and fearful of death when facing a disturbing situation, particularly because they detect certain signs ${ }^{(3,21)}$. Thus, to decrease the child's anxiety, mothers may take the opportunity to talk to the child about cancer, explaining the treatment and care and listening to the child's concerns about the disease ${ }^{(2)}$.

Some mothers clearly and directly disclosed the disease to the children to construe the experience as a natural phenomenon and to provide hope, though discussing death is more difficult, as evidenced by the following mother statement:

"They [children] are well aware of my disease and its severity. I never hid anything from them. [...] They know everything, everything, everything about my disease. My boys are well informed about it; since the day I became ill, I explained to them what I had and the severity of the disease. They are well aware of my disease". (Tulip)

The participants' statements show that as difficult as discussing cancer might be, some mothers nevertheless try to do so frankly to share what they are experiencing and to prepare the children for possible consequences of the disease. 
Therefore, disclosing the disease may help the children to overcome concerns and to further support the sick mother ${ }^{(14)}$. When the readjustment of family dynamics is necessary to cope with a parent's disease, open communication in the family is a key adjustment resource because it helps children understand what the mother is experiencing ${ }^{(17)}$. Furthermore, frank communication may bring the family closer together and strengthen the mother-child bond ${ }^{(14)}$, thereby improving the diseasecoping conditions because disclosing the cancer and its possible consequences may ease the mother's suffering, decrease her depression and anxiety levels and reassure her because she has nothing to hide from the family ${ }^{(2)}$.

Although mothers acknowledge the need to communicate about the disease, some mothers strive to make this communication sporadic, communicating only when necessary.

"I already talked about it and explained what was going to happen. [...]. But we don't talk about it all the time. [...]. We [couple] explain to them [children] that [the tumor] was already smaller than it used to be, but we don't talk to them about it all the time, especially to avoid worrying them. I think that they should enjoy life and be children. They should know what is going on, but we do not need to emphasize the topic because it could easily affect them". (Lily)

The above excerpt highlights the attempt to avoid overloading the daughters with information about the mother's disease, providing only simple details about the progression of the disease to avoid alarming the children and to maintain their routine. This behavior is commonly displayed by mothers who decide to provide less information on cancer to prevent the children from suffering ${ }^{(12)}$.

In some specific cases of mothers with breast cancer, the mothers' concern with the possibility of their daughters becoming ill in the future was indicated as the reason for disclosing the diagnosis to the daughters:

"Yes [I talk about the disease to the children], especially to "S" [daughter]. Because it is always at the back of my mind that this is a female cancer, and I am afraid, but it can happen to her, right?" (Hydrangea)

As shown, frank communication with the child about the mother's cancer may create space for both mother and child to reflect on the impact of the disease on their lives and to change their behaviors to enhance mutual support and care concerning each other's health ${ }^{(17)}$. Furthermore, talking about cancer brings the mother and child closer together, which may generate affective closeness that allows them to express feelings about the disease to each other. This result was identified in the discourse of mothers who had breast cancer, as they were willing to talk to their daughters about their disease to provide information to ensure their daughters' awareness of the situation and to provide them the necessary knowledge for disease prevention.

Some mothers understand the need to communicate with their children using resources such as characters or stories to explain the disease:

"I was sick, I had cancer, which was a bug inside my breast that, if I left it there, it would get worse, so I had to remove it. [...] But I didn't explain to them what it [the 
treatment] was; I explained that is was a little serum that [I] took, which weakened me and caused my hair loss. Then, I addressed the hair issue". (Hydrangea)

Considering the age of the children with whom mothers intend to discuss cancer, the mothers' language must be adapted to the children's reality to make it easier for the children to understand what is happening to the mother ${ }^{(10,12,14)}$. In addition to facilitating the children's understanding, mothers' use of this resource of language highlights the parents' care in identifying the children's needs and abilities to process information. Communicating with small children about the disease may be facilitated by telling stories, playing games or using children's language ${ }^{(22)}$. Telling stories and/or creating characters may increase family interaction and strengthen bonds because the situation may also foster a family relationship of welcoming and listening to the child's needs ${ }^{(23)}$. Therefore, through games, mothers open themselves to the possibility of answering their children's questions and decreasing the children's concern in a way that makes sense to the children.

One mother also reported that she tried to discuss the disease and the treatment but that her daughter was unwilling to listen.

"I approached the subject of my disease, then she [daughter] says, "Mom, hush, you are not sick; we are here to help!". Then, she changes the subject; she does not want to talk. I don't know if this hurts here, but I stay silent. I don't say much, so I prefer to stay quiet to avoid hurting her. Or she does not realize what the disease is because she is only eight years old, right? So, I think that in her little head, I think that this is still too much for her. I try to explain. But she doesn't want to talk about it, she doesn't want to know, she doesn't want to know much about it. [...] I start to talk to her about it, but when I start to talk, she turns around and walks away; she doesn't want to know about it. My girl does not want to know about the disease. I talk about the disease, and she gets angry. She doesn't listen to me. She said: "Mom, not that, I don't want you to talk about it". (Tulip)"

The daughter's dodging and even refusal to speak about and accept the idea of the mother's disease is clear. This avoidance can be explained by the daughter's difficulty in imagining the possible consequences of the disease, including her mother's suffering and possible death ${ }^{(3,17,24)}$. Children may also show behavioral changes as a way to express the suffering caused by the mother's disease, including expressions of sadness, anger, confusion, aggressiveness, rebellion or hostility ${ }^{(3,6-8)}$. Amid this suffering, children must be made to feel safe to talk about the disease and to foster a mutually supportive relationship with their mothers ${ }^{(17)}$.

\section{Category 2: Cancer was not disclosed to the children}

Some mothers explained they had not disclosed the disease to their children for different reasons. Some mothers do not intend to disclose the disease, others plan to disclose it in the future, and others believe that the child already knows. These three reasons can be mapped to the following subcategories. 


\subsection{Mother did not disclose her cancer to the child and does not want to discuss it}

The non-disclosure of the disease to the children may be deliberate. In this case, mothers choose not to communicate about the disease because they believe that they can thus prevent their children from suffering due to their health status. Aspects of this category can be identified in the following transcript:

“No. I don't talk about it much. I don't put many ideas in their [children's] heads... it's difficult because this is my viewpoint... I don't, I don't want to [talk about it]. You know, putting ideas like this in their heads. That mom will one day... who knows, die from this disease and so on. I don't want to put this idea in their heads, that the day when I die may come, you know. So, at least they are not thinking about it, you know, this is what I think. I don't want to worry anyone. (Daisy)"

Daisy's justification for not talking to her son about the disease is that she would thus be protecting him from the concern this information could generate. Facing this challenge, coping with illness, mothers may resist talking to their children to protect them from the impact of this news and thus to prevent negative emotional repercussions for their children, such as anxiety and stress $(2,10) 6,8$ or 10 years. Furthermore, avoiding the responsibility of talking to children about the disease may allow mothers to avoid directly facing their own reality (7).

Although not clearly stated by the participants in their statements, mothers who do not want to talk about their illness typically try to preserve their daily routine and to hide their suffering and concern when they are around their children. These mothers also attempt to conceal the physical changes caused by the treatment from the children to prevent the children from perceiving signs of the disease (2). Although studies indicate that the lack of open communication about the disease may intensify the mother's and children's suffering $(3,4)$, resorting to denial temporarily helps mothers to continue their daily routines and to avoid thinking that they may not be present in the lives of their children in the future.

\subsection{Mother did not disclose the disease to the child but plans to discuss it in the future}

The non-disclosure of the cancer diagnosis to the child may also result from mothers' uncertainty concerning the best time to do so, which implies postponing this conversation with the children, as expressed in the following report:

"When she [the daughter] is older, then yes [the mother intends to talk about the disease]. Because now she's still young, maybe she won't understand very much. But when she is older and she already understands things... I'll find a day to sit down with her and talk about everything that happened, even tell her to be somewhat careful when she is older. (Dalia)"

The participant statement reveal the intention to talk to children about the disease in the future because the mothers believe that the children may be unprepared to 
engage with the situation or that the children may not be focused on the disease at the time. Despite the lack of direct and clear communication with the children about the mothers' illness, this absence of communication neither prevents children from perceiving changes in their mothers' bodies and health nor curtails their curiosity ${ }^{(2,6)}$. Furthermore, some mothers in this situation believe that their children would not understand the illness because of their young age and therefore postpone the conversation about the illness to a time that they believe would be more appropriate ${ }^{(1,2)}$. The mother's postponement of the conversation may indicate that she emphasizes her children's inability to understand or that she is unprepared to respond to her children's curiosity. Although mothers indicate their willingness to talk about the disease in the future, none of them explained how they intend to do so. This finding demonstrates that although mothers are certain that they will address this issue in the future, they nonetheless lack knowledge of how best to do so.

\subsection{Mother did not disclose the disease but believes that her child knows about it}

For some mothers, formally setting a time to disclose the disease and to discuss its possible implications and consequences is unnecessary because the disease becomes evident through the visible changes caused by the disease that are moreover accepted as normal by the family. Therefore, some mothers think that their children know about their health status, and the mothers even talk about it without establishing a specific time to disclose the diagnosis:

"For me, this is something very natural. I don't need to sit down one day and say: "Listen up, daughter, I have to tell you about something very important, something serious". No, something happened, and now and then, I see that people are embarrassed [talking about the disease to others close to the daughter]. (Magnolia)"

Magnolia's statement shows that although she did not disclose the disease to her daughter, she shows no refusal or resistance to discuss it. Despite some mothers' difficulty in discussing the disease with their children because of not knowing how to address the subject or what to say, some mothers may share information about their disease and health status to protect their children and to prepare them to cope with $\mathrm{it}^{(1,2)}$. Moreover, when mothers realize that their children are worried or ask about what is happening to them, mothers ultimately share information and emotions within the family ${ }^{(2)}$, thus strengthening their relationship with their children.

\section{Conclusion}

The results indicate that sharing and discussing the disease with their children is very difficult for sick mothers. The findings also reveal that both mothers who maintain a frank conversation about cancer and those who believe that their child is too young or has no reason to know about the disease require assistance with this situation. The study also showed that even when deciding to disclose the disease to children, mothers are uncertain how to do so. Nonetheless, truth is a key element in helping 
a child cope with the mother's disease, and for the child to understand the situation, the information should be communicated in a manner consistent with the child's vocabulary, that is, the language may be playful, respecting the child's emotional reactions.

The results highlight the necessity of supporting families affected by cancer in terms of mother-child communication, particularly families in which the mother has a weak support network. the study highlights that healthcare professionals should be prepared to help and guide parents about the importance and the way to communicate with their young children about the mother's disease. In addition, professional should pay attention to the family context, helping and supporting mothers in not only coping with the disease but also facing daily situations, such as disclosing cancer to a child.

\section{References}

1. Tavares R, Brandão T, Matos PM. Mothers with breast cancer: A mixed-method systematic review on the impact on the parent-child relationship. Psychooncology [Internet]. 2017 ;27::367-75. doi:10.1002/pon.4451

2. Asbury N, Lalayiannis L, Walshe A. How do I tell the children? Women's experiences of sharing information about breast cancer diagnosis and treatment. Eur J Oncol Nurs 2014;18:564-70. doi:10.1016/j.ejon.2014.07.003

3. Shah BK, Armaly J, Swieter E. Impact of parental cancer on children. Anticancer Res 2017 20;37: 4025-8. doi:10.21873/anticanres. 11787

4. Prouty CD, Mazor KM, Greene SM, Roblin DW, Firneno CL, Lemay CA, et al. Providers' perceptions of communication breakdowns in cancer care. J Gen Intern Med 2014; 6;29:1122-30. doi: 10.1007/s11606-014-2769-1

5. Fitch MI, Allard M. Perspectives of husbands of women with breast cancer: Impact and response. Can Oncol Nurs J 2007;17:66-71. doi:10.5737/1181912x1726671

6. McPherson G. Children of mothers with breast cancer were distressed by hair loss; those $>10$ years of age wanted more information about their mother's condition. Evid Based Nurs 2007;10:29. doi: 10.1136/ebn.10.1.29

7. Castro EK, Job C. Câncer na Mãe e o Impacto Psicológico no Comportamento de Seus Filhos Pequenos. Gerais Rev Insterinstitucional Psicol 2010;3:136-48.

8. Visser A, Huizinga GA, van der Graaf WTA, Hoekstra HJ, Hoekstra-Weebers JEHM. The impact of parental cancer on children and the family: A review of the literature. Cancer Treat Rev 2004;30:683-94. doi:10.1016/j.ctrv.2004.06.001

9. Huizinga GA, Visser A, Zelders-Steyn YE, Teule JA, Reijneveld SA, Roodbol PF. Psychological impact of having a parent with cancer. Eur J Cancer 2011;47:S239-46. doi:10.1016/S0959-8049(11)70170-8

10. Muñoz Sastre MT, Sorum PC, Mullet E. Telling children their mother is seriously ill or dying: Mapping French people's views. Child Care Health Dev2016;42 :60-7. doi:10.1111/cch. 12270

11. Phillips F. Adolescents living with a parent with advanced cancer: a review of the literature. Psychooncology 2014;23:1323-39. doi:10.1002/pon.3570

12. Cho O-H, Yoo Y-S, Hwang K-H. Comparison of parent-child communication patterns and parental role satisfaction among mothers with and without breast cancer. Appl Nurs Res 2015;28:163-8. doi: 10.1016/j.apnr.2014.09.005 
13. Fisher C, O'Connor M. "motherhood" in the context of living with breast cancer. Cancer Nurs 2012;35:157-63. doi: 10.1097/NCC.0b013e31821 cadde.

14. Kim S, Ko YH, Jun EY. The impact of breast cancer on mother-child relationships in Korea. Psychooncology 2012;21:640-6. doi: 10.1002/pon.1941

15. Gazendam-Donofrio S, Hoekstra H, Van der Graaf W, Van de Wiel H, Visser A, Huizinga $\mathrm{G}$, et al. Parent-child communication patterns during the first year after a parent's cancer diagnosis. Cancer 2009; 15;115):4227-37. doi: 10.1002/cncr.24502

16. Brédart A, Bouleuc C, Dolbeault S. Doctor-patient communication and satisfaction with care in oncology. Curr Opin Oncol 2005;17:351-4. doi:10.1097/01. cco.0000167734.26454.3017.

Bekteshi V, Kayser K. When a mother has cancer: pathways to relational growth for mothers and daughters coping with cancer. Psychooncology 2013;22: 2379-85. doi: 10.1002/pon.3299

18. WHO (World Health Organization). Young people's health — A challenge for society. Report of a WHO Study Group on Young People and "Health for All by the Year 2000." Genebra; 1986.

19. Laville C, Dionne J. A construção do saber: manual de metodologia da pesquisa em ciências humanas. 1st ed. Porto Alegre: Artmed; 1999. 344 p.

20. Tong A, Sainsbury P, Craig J. Consolidated criteria for reporting qualitative research (COREQ): a 32-item checklist for interviews and focus groups. Int J Qual Heal Care 2007 16;19:349-57. doi:10.1093/intqhe/mzm042

21. Kühne F, Krattenmacher T, Beierlein V, Grimm JC, Bergelt C, Romer G, et al. Minor children of palliative patients: A systematic review of psychosocial family interventions. J Palliat Med 2012;15:931-45. doi: 10.1089/jpm.2011.038022. Rindstedt C. Children's strategies to handle cancer: a video ethnography of imaginal coping. Child Care Health Dev 2014;40:580-6. doi: 10.1111/cch.12064

23. Angeli A do AC de, Luvizaro NA, Galheigo SM. O cotidiano, o lúdico e as redes relacionais: a artesania do cuidar em terapia ocupacional no hospital. Interface - Comun Saúde, Educ [Internet]. 2012 Mar;16(40):261-72. Available from: http://www.scielo.br/ scielo.php?script $=$ sci_arttext\&pid $=$ S1414-32832012000100020\&lng=pt\&tlng=pt

24. Raveis VH, Pretter S. Existential plight of adult daughters following their mother's breast cancer diagnosis. Psychooncology 2005;14:49-60. doi:10.1002/pon.819 